OPEN ACCESS

Edited by:

Leslie A. Weston,

Charles Sturt University, Australia

Reviewed by:

Ilias Travlos,

Agricultural University of

Athens, Greece

Saliya Gurusinghe,

Charles Sturt University, Australia

${ }^{*}$ Correspondence:

Stéphane Cordeau

stephane.cordeau@inrae.fr

TORCID:

Stéphane Cordeau orcid.org/0000-0003-1069-8388

Richard G. Smith orcid.org/0000-0002-3571-5888

Nicolas Munier-Jolain orcid.org/0000-0002-0871-3692

Guillaume Adeux orcid.org/0000-0003-0903-391X

Specialty section:

This article was submitted to

Weed Management,

a section of the journal

Frontiers in Agronomy

Received: 03 September 2021 Accepted: 20 December 2021

Published: 27 January 2022

Citation:

Cordeau S, Baudron A, Busset $H$,

Farcy $P$, Vieren $E$, Smith $R G$

Munier-Jolain N and Adeux G (2022)

Legacy Effects of Contrasting

Long-Term Integrated Weed

Management Systems.

Front. Agron. 3:769992.

doi: 10.3389/fagro.2021.769992

\section{Legacy Effects of Contrasting Long-Term Integrated Weed Management Systems}

\author{
Stéphane Cordeau ${ }^{1 \star t}$, Auxence Baudron ${ }^{1}$, Hugues Busset ${ }^{1}$, Pascal Farcy ${ }^{2}$, Eric Vieren ${ }^{1}$, \\ Richard G. Smith ${ }^{3 \dagger}$, Nicolas Munier-Jolain ${ }^{1 \dagger}$ and Guillaume Adeux ${ }^{1 \dagger}$ \\ ${ }^{1}$ Agroécologie, AgroSup Dijon, INRAE, Université de Bourgogne, Université de Bourgogne Franche-Comté, Dijon, France, \\ 2 Unité Expérimentale du Domaine d'Epoisses, INRAE, U2E, Bretenière, France, ${ }^{3}$ Department of Natural Resources and the \\ Environment, University of New Hampshire, Durham, NH, United States
}

To reduce reliance on herbicides and maintain crop productivity, integrated weed management (IWM) seeks to optimize synergies between diverse sets of weed management practices combined at the cropping system scale. Nevertheless, data on weed community response to the long-term implementation of IWM practices remain scare. Here, we assessed the effects of four IWM systems with contrasting objectives and practices (S2: transition from superficial tillage to conservation agriculture; S3: no-mechanical weeding; S4: mixed mechanical and chemical weeding; S5: herbicide-free; all with 6 year rotations) compared to a conventional reference (S1: herbicide-based with systematic plowing and a 3 year rotation) on taxonomic and functional weed community composition and structure after 17 years of continuous implementation. We examined the legacy effects of these systems with a uniformity trial consisting of winter wheat managed uniformly across the systems as well as with a novel in situ weed seedbank approach involving tilled strips. We found that resulting weed communities in IWM systems were more species rich (species richness from 1.1 to 2.6 times greater) and more abundant (total density from 3.3 to 25 times greater) than those observed in the reference system, and differed in term of taxonomic and functional composition. In addition, we found that, when systems shared the same weed species, germination patterns of two thirds of the species differed between systems, highlighting the selection pressures some IWM practices exert on weeds. We showed that analyzing the superficial germinable seedbank in situ with tilled strips could provide a comprehensive view of resulting weed communities and be helpful in developing cropping systems that foster agroecological weed management.

Keywords: seedbank, uniformity trial, no-till, herbicide reliance, weed community, functional trait, germination pattern

\section{INTRODUCTION}

Effective weed management is recognized as crucial for the ecological intensification of agriculture (Petit et al., 2015) because weeds can generate severe yield losses (Oerke, 2006) and current approaches to weed management rely heavily on herbicides. To reduce herbicide reliance and maintain crop productivity, integrated weed management (IWM) strategies aim to both disrupt 
weed population dynamics and reduce weed interference by coherently combining a diversity of chemical, physical, and cultural weed management practices at the cropping system scale (Harker, 2013). Ideally, these practices are combined in ways that optimize synergistic interactions among practices by targeting weeds in complementary ways and at different stages in their life cycles (Ryan et al., 2011). In doing so, effective IWM strategies keep weed populations below economic thresholds while maintaining or enhancing weed diversity (Liebman and Gallandt, 1997). However, there are surprisingly few examples of long-term research comparing different combinations of IWM practices on weed communities, which could enable the identification of successful IWM approaches and facilitate decision making (Harker and O'donovan, 2013). An effective IWM strategy must diversify selection pressures in time to avoid shifts toward weed communities dominated by competitive species (Adeux et al., 2019b) or those adapted, either via evolution or morphological or phenological plasticity, to avoid or resist management (Menalled et al., 2016). The degree to which contrasting IWM strategies can shift the ecology and/or biology of arable weeds over the long-term is largely unexplored but of critical importance to move toward more sustainable alternatives to herbicides (Neve et al., 2018).

Long-term cropping system experiments can be powerful tools with which to compare the short and longer-term outcomes of contrasting IWM strategies aimed at controlling weeds while reducing herbicide reliance (Adeux et al., 2019a). Lechenet et al. (2017) reviewed experimental designs for cropping system experiments intended to test pest management principles. They concluded that to ensure an efficient comparison of cropping systems, the most complete design requires the implementation of (i) temporal replicates of the cropping systems where all the crops of the crop sequence are cultivated each year (i.e., all entry points), and (ii) spatial replicates where all entry points are replicated within blocks the same year. Unfortunately, most experimental designs of cropping system experiments do not include both aspects because of space or labor issues and are therefore prone to misinterpret the temporal dynamics of the response variables (Lechenet et al., 2017). Diversified crop sequences appear as a critical component of IWM across a diversity of situations (Weisberger et al., 2019) because each crop and its associated practices will act as a set of filters that can disrupt different phases of the weed species' life cycle (Derksen et al., 2002). However, when cropping system experiments lack temporal replicates, weeds are rarely assessed across a common baseline, i.e., the same crop cultivated the same year in all plots. To overcome this issue, previous studies have investigated either the weed seedbank as a method for revealing the effects of past practices (Bàrberi and Lo Cascio, 2001) or the weed flora emerging in a reference crop as part of a uniformity trial (Brown and Gallandt, 2018). Rarely are both of these approaches implemented together (Jernigan et al., 2017). Uniformity trials-in which a standard agronomic treatment is applied across all plots at the end of a cropping system experiment in order to partition of variability due to previous cropping system effects, without any confounding effects-can provide critical insight on the legacy effects associated with the integration of practices across diverse crop rotations (Jernigan et al., 2017).

The objective of this study was to quantify weed seedbank and emerged weed communities after 17 years of five contrasting IWM strategies in a long-term cropping system experiment. The nature and magnitude of these legacy effects were assessed in a reference crop (winter wheat) managed uniformly across the cropping system experiment in year 18. We hypothesized that weed seedbanks would be more diverse (both in term of taxonomic and functional diversity) and more abundant in the IWM systems compared to the reference system due to the higher diversity of crop functional types (winter annuals, summer annuals, etc.) in the IWM systems coupled with incomplete control of weeds in each crop. Secondly, we hypothesized that weed community composition would differ both taxonomically and functionally among the contrasting IWM systems, due to differences in their overarching management strategies (e.g., balance between chemical, physical, and cultural approaches to weed management). Finally, we hypothesized that some weeds would exhibit shifts in their germination phenology (manifesting in differences in the timing and duration of peak emergence from the soil seed bank) across contrasting IWM systems due to different selection pressures imposed by each system.

\section{MATERIALS AND METHODS}

\section{Experimental Site and Set-Up}

The field experiment was conducted at the INRAE experimental farm in Bretenière $\left(47^{\circ} 14^{\prime} 11.2^{\prime \prime} \mathrm{N}, 5^{\circ} 05^{\prime} 56.1^{\prime \prime} \mathrm{E}\right), 15 \mathrm{~km}$ southeast of Dijon, France. The experiment was set up as a randomized complete block design (two blocks separated by $1 \mathrm{~km}$ ) and included five cropping systems with contrasting IWM objectives and practices. The reference cropping system (S1) was characterized by a 3-year oilseed rape-winter wheat-winter barley rotation, systematic moldboard plowing in summerautumn, and herbicides as the sole curative weed management tool. S1 is a typical grain-based cropping system of the Burgundy region, designed to maximize financial return. The other four cropping systems ( $22, \mathrm{~S} 3, \mathrm{~S} 4$, and S5) were designed to mimic contrasting agronomic pathways that farmers might implement to reduce herbicide reliance and resulted in a more complex 6 -year rotation. The complete crop sequence is detailed in Supplementary Table 1. Crop rotations in S2, S3, S4, and S5 systems were made of three winter sown crops (winter wheat, winter barley, triticale, or faba bean), autumn sown oilseed rape, one spring crop (oat, sugarbeet, faba bean, lupin, spring barley, or mustard) and one summer sown crop (maize, sorghum, soybean, or sunflower). Hence, winter wheat and oilseed rape, the two most common crops of the region, were present throughout the five CS. Sugar beet was only cropped in S4 (up to 2006 when the nearby sugar refinery plant closed). In S5, perennial forage crops such as alfalfa were included in order to manage Canada thistle (Cirsium arvense) or bitter dock (Rumex obtusifolius). Similarly, in S3, companion crops (such as faba bean, lentil, vetch, flax) were intercropped in oilseed rape to cover interrows before winter. 
System S2 represented a typical transition from a reduced tillage system (i.e., no inversion tillage from 2001-2010) to notill conservation agriculture (2010-2017). S2 was designed to reduce labor requirement and time consuming operations. In contrast, systems S3, S4, and S5 all implemented moldboard plowing every 2 years on average over the 2001-2017 period. Herbicides were used as the sole method of direct weed control in S2 and S3. This choice was made in coherence with the strategy of minimum soil disturbance in S2 and to reflect the wish of certain farmers to not invest in mechanical weeding tools in S3. Weed management relied on mechanical tools and herbicides in S4 and only on mechanical tools in S5 (Adeux et al., 2019a). In addition, the four alternative systems also implemented a wide array of preventive and cultural weed management tools such as false seedbed technique, delayed sowing of winter cereals, and higher seeding rates. S4 aimed to be the typical IWM system, resorting preferentially to preventive measures, and mechanical weeding. However, applications of specialized herbicides on target species remained possible when weather conditions were not suitable for mechanical weeding or to control weeds with low sensibility to mechanical weeding.

The set of decision rules characterizing each of the five cropping systems was replicated on two blocks, resulting in 10 plots of 1.7 ha each on average. A complete description of the long-term cropping system experiment (crop sequence-see Supplementary Table $\mathbf{1}$-and associated management, including tillage intensity/frequency, herbicide use/types, mechanical weeding, etc.) implemented from 2000 to 2017 is available in Adeux et al. (2019a, 2022) and synthesized in Table $\mathbf{1}$.

In 2017-2018, a uniformity trial with winter wheat was established across the experimental site in order to examine the legacy effects of the previous cropping systems. Soil preparation prior to sowing winter wheat consisted in stubble cultivation to $8 \mathrm{~cm}$ deep $(10 / 10 / 17)$ and rotary harrowing, also $8 \mathrm{~cm}$ deep $(13 / 10 / 17)$. All fields were sown with winter wheat (variety "Nemo") at a rate of 350 seeds. $\mathrm{m}^{-2}$ and a sowing depth of $3 \mathrm{~cm}$ $(15 / 10 / 17)$. Sowing was performed with a mechanical seed drill (Amazone D9) set at a $13.8 \mathrm{~cm}$ row spacing. Nitrogen fertilization was split into two applications, i.e., $50 \mathrm{~kg} \mathrm{~N} \cdot \mathrm{ha}^{-1}$ on 22/02/18 and $116 \mathrm{~kg} \mathrm{~N} \cdot \mathrm{ha}^{-1}\left(+33 \mathrm{~kg} \mathrm{~S} . \mathrm{ha}^{-1}\right)$ on 10/04/18. Septoria leaf spot was controlled on $07 / 05 / 18$ with $50 \mathrm{~g} \mathrm{ha}^{-1}$ of benzovindiflupyr, $40 \mathrm{~g} \cdot \mathrm{ha}^{-1}$ of cyproconazole, and $375 \mathrm{~g}^{-\mathrm{ha}^{-1}}$ of chlorothalonil. Wheat yellow rust was controlled on 16/05/18 with 50 g.ha ${ }^{-1}$ of benzovindiflupyr. Weed control in winter wheat was performed late (one application of herbicide on $22 / 03 / 18$ ) so as to allow full expression of the autumn- and spring-emerging weed flora and consisted in a tank mixture of $9 \mathrm{~g}^{\mathrm{h}} \mathrm{ha}^{-1}$ of mesosulfuron, 60 g.ha ${ }^{-1}$ of diflufenican, 3 g.ha ${ }^{-1}$ of iodosulfuron, and 25 g.ha ${ }^{-1}$ of amidosulfuron.

\section{Measurements \\ Weed Seedbank Assessments}

During the cropping system experiment phase (i.e., 2001-2017), the soil seedbank was assessed in 2001, 2002, 2003, 2005, and 2010, and not repeated afterwards, by collecting 10 soil samples per field each year (each sample being a composite of 10 soil cores, $4.5 \mathrm{~cm}$ diameter, $30 \mathrm{~cm}$ depth) from the same $100 \mathrm{~m}^{2}$ zone in each field each year. Each core was split into superficial (0$10 \mathrm{~cm}$ depth) and deep $(10-30 \mathrm{~cm})$ soil horizons before pooling. The weed seeds were extracted from the soil samples using a sieving method (with different sieves until $400 \mu \mathrm{m}$ ) and then submitted to a germination bioassay in greenhouse (Mahé et al., 2021). The emerged seedlings of each species were identified at the species level (when possible) and counted. After 1 year of succeeding cohorts, the residual seeds were identified and counted under a dissecting scope. Based on the diameter of the soil probe, seedbank density was then expressed as seed.m ${ }^{-2}$, both in the superficial and deep soil horizons.

Legacy effects of the cropping systems on the germinable soil seedbanks were assessed in situ during the uniformity trial (i.e., 2017-2018) using a false seedbed technique. Seedling emergence from the superficial seedbank was stimulated by shallowly tilling $(10 \mathrm{~cm}$ depth) two strips per field ( $4 \mathrm{~m}$ wide, about $200 \mathrm{~m}$ long) every 6 weeks during the autumn and spring growing seasons (except when weather conditions were unsuitable for implementing tillage, Supplementary Figure 1). In total, six sessions of tillage were implemented $(05 / 08 / 2017$, 14/09/2017, 29/10/2017, 13/02/2018, 12/04/2018, 25/05/2018; Supplementary Table 2). Weed surveys, in which all emerged seedlings within $100.36 \mathrm{~m}^{2}$ quadrats per strip were identified and counted, were performed immediately prior to each tillage session, i.e., approximatively 6 weeks after the previous tillage $(12 / 09 / 2017,25 / 10 / 2017,06 / 12 / 2017,09 / 04 / 2018$, 18/05/2018, 18/06/2018; Supplementary Table 2) so as to allow the maximum number of individuals of each species to emerge (Cordeau et al., 2017b).

\section{Weed Communities in the Uniformity Trial}

The legacy effect of cropping systems on weed communities was also investigated by assessing emerged weed flora in a winter wheat crop uniformity trial. Weed community composition was assessed before weed control (08/02/18) in eight $16 \mathrm{~m}^{2}$ zones per plot. No herbicide or mechanical weeding was done in autumn or early spring, prior to the weed survey, to capture maximum weed diversity. Weeds were identified at the species level (when possible) and the abundance of each species in the $16 \mathrm{~m}^{2}$ area was estimated visually using the scale of abundance developed by Barralis (1976) with sux classes (one individual, $<1$ individuals $\mathrm{m}^{-2}, 1-2,3-20,21-50$, and 51-500 individuals. $\mathrm{m}^{-2}$ ). Total weed abundance was computed using the center of each class $(0.06,0.5$, $1.5,11.5,35.5$, and 275 individuals. $\mathrm{m}^{-2}$, respectively) to allow the aggregation of individual species' abundances. Species richness was computed as the number of weed species per $16 \mathrm{~m}^{2}$ zones. Community weighted means (CWM, average value of a given attribute weighted by the relative abundance of each species) were also computed on three attributes [height, seed mass, specific leaf area (SLA)] reflecting weed community response to past agricultural practices (Storkey et al., 2010; Gaba et al., 2017).

\section{Statistical Analysis}

All analysis were carried out at the soil sample (seedbank in the cropping system experiment), quadrat (superficial germinable seedbank in uniformity trial) or $16 \mathrm{~m}^{2}$ zone level (weed survey 
TABLE 1 | Differences in terms of farming practices between experimented cropping systems (over the 2012-2017 period).

\begin{tabular}{|c|c|c|c|c|c|c|}
\hline Farming practices & $\begin{array}{l}\text { Experimented cropping } \\
\text { system effect }(d f=4)\end{array}$ & S1 & S2 & S3 & S4 & S5 \\
\hline Plowing frequency & $F=47.67, P=0.001$ & $0.83 \pm 0.00 c$ & $0.00 \pm 0.00 a$ & $0.42 \pm 0.12 b$ & $0.42 \pm 0.12 b$ & $0.67 \pm 0.00 \mathrm{bc}$ \\
\hline $\begin{array}{l}\text { Average number of false seedbed } \\
\text { operations year }^{-1}\end{array}$ & $F=7.24, P=0.041$ & $1.75 \pm 0.12 \mathrm{ab}$ & $0.00 \pm 0.00 a$ & $2.58 \pm 0.59 b$ & $2.67 \pm 0.24 b$ & $2.08 \pm 1.30 a b$ \\
\hline $\begin{array}{l}\text { Frequency of delayed sowing of } \\
\text { winter cereals }\end{array}$ & $F=12.53, P=0.016$ & $0.00 \pm 0.00 a$ & $0.75 \pm 0.35 b$ & $0.83 \pm 0.24 b$ & $1.00 \pm 0.00 b$ & $0.58 \pm 0.12 \mathrm{ab}$ \\
\hline Average $\mathrm{HTFI}_{\text {year }}{ }^{-1}$ & $F=32.31, P=0.003$ & $1.34 \pm 0.18 \mathrm{bc}$ & $1.97 \pm 0.18 c$ & $0.82 \pm 0.26 a b$ & $0.50 \pm 0.16 a$ & $0.00 \pm 0.00 a$ \\
\hline Average HTFI before sowing year ${ }^{-1}$ & $F=639.7, P<0.0001$ & $0.02 \pm 0.02 a$ & $1.05 \pm 0.06 b$ & $0.02 \pm 0.03 a$ & $0.01 \pm 0.01 a$ & $0.00 \pm 0.00 a$ \\
\hline $\begin{array}{l}\text { Average number of mechanical } \\
\text { weeding operations year }{ }^{-1}\end{array}$ & $F=37.38, P=0.002$ & $0.00 \pm 0.00 a$ & $0.00 \pm 0.00 a$ & $0.17 \pm 0.24 a$ & $1.83 \pm 0.00 b$ & $2.92 \pm 0.58 b$ \\
\hline $\begin{array}{l}\text { Average nitrogen fertilization } \mathrm{kg} \mathrm{N} \\
\text { year }^{-1}\end{array}$ & $F=29.14, P=0.003$ & $154 \pm 8 b$ & $94 \pm 6 a$ & $96 \pm 5 a$ & $109 \pm 2 a$ & $79 \pm 12 a$ \\
\hline Proportion of autumn-sown crops & $F=6.00, P=0.055$ & $0.67 \pm 0.04 b$ & $0.50 \pm 0.04 a b$ & $0.50 \pm 0.04 a b$ & $0.50 \pm 0.04 a b$ & $0.42 \pm 0.04 a$ \\
\hline Number of crops & $F=8.60, P=0.03$ & $3.00 \pm 0.35 a$ & $5.00 \pm 0.35 a b$ & $5.50 \pm 0.35 b$ & $5.00 \pm 0.35 a b$ & $5.50 \pm 0.35 b$ \\
\hline Number of sowing periods & Perfect fit* & $2.00 \pm 0.00 a$ & $4.00 \pm 0.00 b$ & $4.00 \pm 0.00 b$ & $4.00 \pm 0.00 b$ & $4.00 \pm 0.00 b$ \\
\hline
\end{tabular}

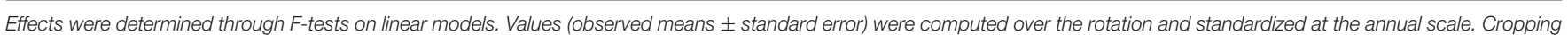
systems sharing identical letters are not significantly different at $P<0.05$.

*Perfect fit denotes a model where each level of the factor shows no variability, i.e., $R^{2}=1$.

in uniformity trial) with the [lme4] package of the $\mathrm{R}$ software version 3.3.2 (R Development Core Team, 2019). Linear mixedeffects models were used to analyse continuous response variables [ $\log _{10}(x+1)$ transformed weed density, CWM variables] whereas mixed Poisson regression with a log-link was used to analyse whole, non-negative response variables (species richness) and mixed beta-regression with a logit-link were used to analyse proportion data (percent of seeds in the top soil horizon). All response variables were regressed against cropping system, and sometimes in interaction with year (seedbank in the cropping system experiment) or the weed survey session (superficial germinable seedbank). Field and block were considered as random effects in all models to account for the design of the experiment and the sampling design (see the 17-year crop sequences in Supplementary Table 1). Significance of cropping system effects were assessed through type III Wald Chi-squared tests using the ANOVA function of the [car] R package. Contrasts between the cropping systems were adjusted using the [emmeans] $\mathrm{R}$ package. Except for beta-regression, the quality of the model was assessed using marginal $R^{2}$ accounting for the fixed effects $\left(R^{2} m\right)$ and conditional $R^{2}$ accounting for the fixed and random effects $\left(R^{2} c\right)$.

Partial canonical correspondence analysis (pCCA) was performed to visualize and assess cropping system legacy effects on the superficial germinable weed seedbank (all sessions pooled) and emerged weed community composition before weed control in winter wheat. Field and field:block effects were partialled out to highlight cropping system effects. Only species with frequencies of occurrence $\geq 5 \%$ of the quadrats (superficial germinable seedbank) or zone (emerged weeds) were retained and were described by their abundance. Significance of cropping system effects was assessed using permutation-based ANOVA $(N=$ 999 permutations).
To test for differences in species emergence patterns in the superficial germinable seedbank of the uniformity trial, kernel density weighted by the relative abundance of each species at each session was estimated using the density function and the approach described in several recents studies (Perronne et al., 2014; Bourgeois et al., 2019). We computed the dissimilarity of emergence distribution using the overlapTrue function from the [overlap] package. In order to test the significance of the dissimilarities between each pair of systems where the same species was observed, we used a randomization method to determine whether the overlap between species emergence was significantly lower than the null hypothesis (random layout of the weed community between systems). The randomization procedure was implemented by generating random permutations of the variable "cropping system" to randomize the weed emergence in each quadrat at each session. Thus, we generated 10,000 random distributions and implemented a one-tailed direct test of significance for the nonrandom structure. $P$-values were estimated as the proportion of random distributions having a value of overlap lower than the observed overlap.

\section{RESULTS}

\section{Seedbank Dynamics During the Cropping System Experiment}

A total of 53 species were observed in the soil seedbank from 2001 to 2010. The five most abundant species, representing $82 \%$ of total abundance, were Alopecurus myosuroides, Solanum nigrum, Anagallis arvensis, Chenopodium album, and Amaranthus retroflexus. The majority of species (i.e., 50) were found in both the superficial $(0-10 \mathrm{~cm})$ and deep soil horizon $(10-30 \mathrm{~cm})$. Only Veronica agrestis was found solely in the deep soil horizon 


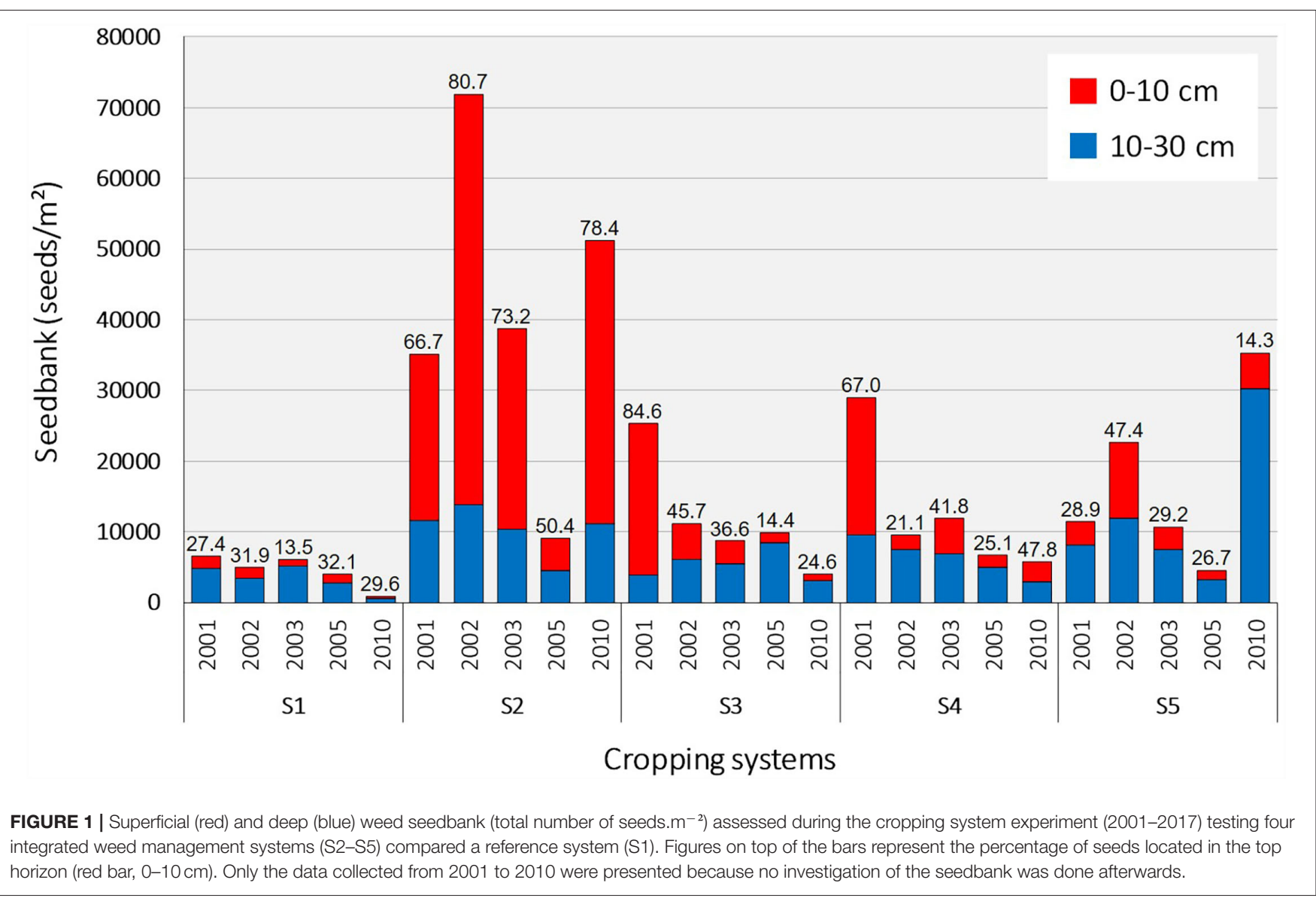

$(10-30 \mathrm{~cm})$ and Medicago sp. and Epilobium sp. were found exclusively in the superficial horizon $(0-10 \mathrm{~cm})$. Total weed seedbank abundance (Figure 1) varied by system; however, the effect of system depended on the year (system: $d f=4, \chi^{2}=$ 27.1, $P<0.001$; year: $d f=4, \chi^{2}=4.9, P=0.30$; system-byyear interaction: $\left.d f=16, \chi^{2}=559.9, P<0.001\right)$. Similarly, the proportion of seeds located in the superficial soil horizon varied by systems $\left(d f=4, \chi^{2}=95.85, P<0.001\right)$, year $\left(d f=4, \chi^{2}=24.6, P<0.001\right)$, and the interaction between both factors $\left(d f=16, \chi^{2}=337.8, P<0.001\right.$ ), averaging $50-$ $80 \%$ in the S2 no-plow system compared to $10-50 \%$ in the other plowing-based systems (except in S3 and S4 in the first year). A total of 45 species were observed the last year that seedbank data were collected in the cropping system experiment (i.e., 2010). The top five most frequent species (in decreasing order) were A. arvensis, Galium aparine, C. album, S. nigrum, and A. myosuroides. Seedbank species richness in 2010 was higher in all alternative IWM systems (S2-S5) than the S1 reference (Table 2). Total seed density in 2010 varied by systems (Table 2) and was highest in the no-plow (S2) and herbicidefree (S5) systems. The proportion of the seedbank located in the superficial soil horizon was higher in S2 than in the plowingbased systems.

\section{Legacy Effect of Cropping Systems in the Uniformity Trial Legacy Effect on the Germinable Superficial Seedbank}

A total of 59 species were observed in the seedbank strips over the 2017-2018 growing season. The most frequent species observed (in decreasing order) were A. myosuroides, C. album, Fallopia convolvulus, S. nigrum, and Chenopodium polyspermum and represented $58.6 \%$ of total abundance observed in the tilled strips over the season. Of the 59 weed species, 33 species were also observed in the 2010 seedbank samples. Species richness and total weed density varied by cropping system (Table 2 ). Specifically, seedbanks in all four IWM systems had higher species richness and were more abundant compared to the reference system (S1). Seedbank community composition also varied by cropping system (Figure $2 \mathrm{~A}, P$-value $=0.002$ ). The first pCCA axis separated systems according to a tillage gradient. The no-plow (S2) system was associated with spring/summer germinating dicots (A. arvenis, Kickia sp., C. polyspermum) and one grass species (Echinocloa crus-galli), whereas the plowingbased (S3) system was associated with autumn-germinating species (Veronica persica, Veronica herderifolia, Viola arvensis). The second axis discriminated cropping systems according to 
their herbicide use, the herbicide-free (S5) system was associated with perennials species (Rumex sp. and C. arvense) and summergerminating annuals (C. album, S. nigrum).

When accounting for the different survey sessions (Figure 3), weed density varied by system $\left(d f=4, \chi^{2}=104.2, P<0.001\right)$, session ( $\left.d f=5, \chi^{2}=78.1, P<0.001\right)$, and the interaction between both $\left(d f=20, \chi^{2}=358.1, P<0.001\right)$. Weed density ranged from 0 to 830.5 plants $/ \mathrm{m}^{2}$ and averaged 41.4 plants $/ \mathrm{m}^{2}$. Overall, total weed density was highest in the spring/summer sessions. This was particularly the case for the no-plow (S2) and herbicide-free (S5), which were the only systems to show the highest abundance in all of the last three sessions. Systems S1 and S2 had the lowest and highest total densities at each of the six sessions, respectively. Species richness (Figure 3) ranged from 0 to 10 species $/ 0.36 \mathrm{~m}^{2}$ quadrat, averaged 2.4 species and varied by system $\left(d f=4, \chi^{2}=62.5, P<0.001\right)$, session $\left(d f=5, \chi^{2}=65.7\right.$, $P<0.001)$, and the interaction between both factors $(d f=20$, $\chi^{2}=12.38, P<0.001$ ). Species richness in all four IWM systems was higher than the reference (S1) in spring sessions.

\section{Legacy Effect on Emerged Communities in Winter Wheat}

In the uniformity trial, a total of 38 weed species were observed prior to herbicide application for weed control in winter wheat. The most abundant species, representing 58.8\% of total abundance, were A. myosuroides, Veronica hederifolia, G. aparine, V. persica, and Stellaria media. Similar to what we observed in the superficial seedbank, A. myosuroides was not associated with a particular system, while other species showed varying levels of association with specific systems (Figure 2). Species richness ranged from 1 to 14 species per $16 \mathrm{~m}^{2}$ zone and averaged 7.25 species per zone. Species richness varied by cropping system (Table 2), with the lowest richness observed in the reference system (S1) and the highest in S2. Total weed density prior to weed control ranged from 0.2 to 319.4 plants. $\mathrm{m}^{-2}$ and averaged 39.2 plants. $\mathrm{m}^{-2}$. Total weed density varied by cropping system (Table 2), and was higher in the four IWM systems compared to the reference system, where weed density was very low (averaging 3.8 plants. $\mathrm{m}^{-2}$ ).

Weed community composition varied by cropping system (Figure 2B, $P$-value $=0.002$, partial variance explained by axis 1 and $2=22.3 \%$ ). The first pCCA axis (accounting for $12.9 \%$ of the partial variance) discriminated the systems according to tillage intensity, whereas the second axis (accounting for $8.4 \%$ of the partial variance) separated systems according to the herbicide use. Several species showed clear associations with system S2, including the perennial species C. arvense, and Asteraceae taxa (Sonchus asper and Lapsana communis), resulting in a community with a higher CWM height than S3 (Table 2). Species associated with system S3 were mostly autumn-germinating short-cycle prostrate species such as $V$. arvensis, Aphanes arvensis, Senecio vulgaris, V. persica, and V. hederifolia, resulting in a community of low height (Table 2). Species associated with S5 were fewer; however, the high density and frequency of S. media, Rumex sp., and Fumaria officinalis (Figure 2B) resulted in a community with a high SLA (Table 2). 


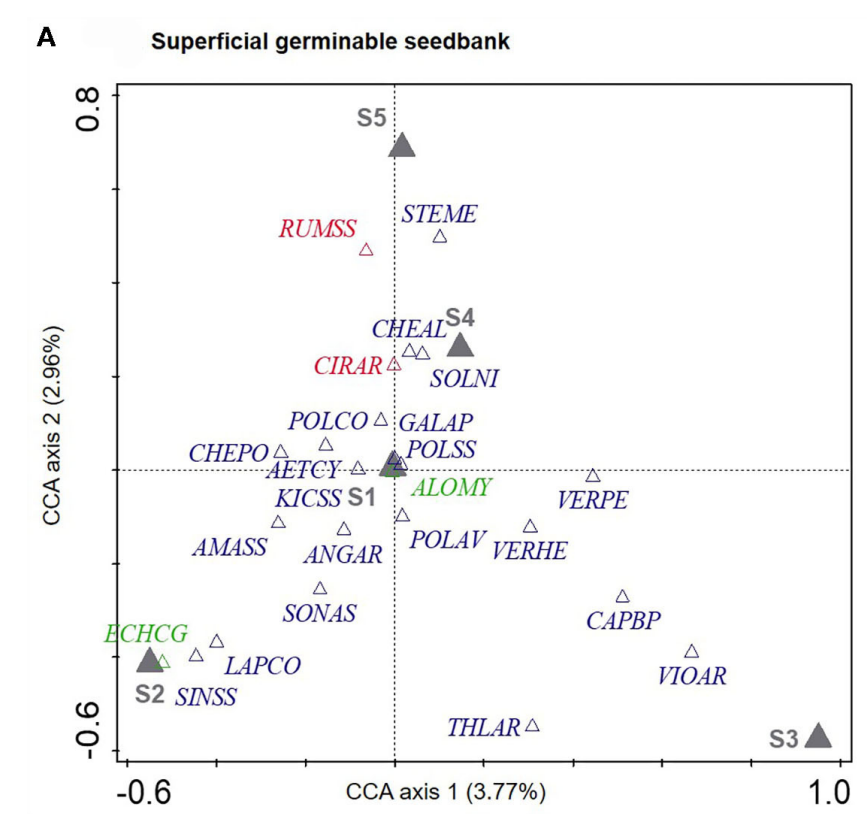

\section{B} Emerged seedlings in winter wheat

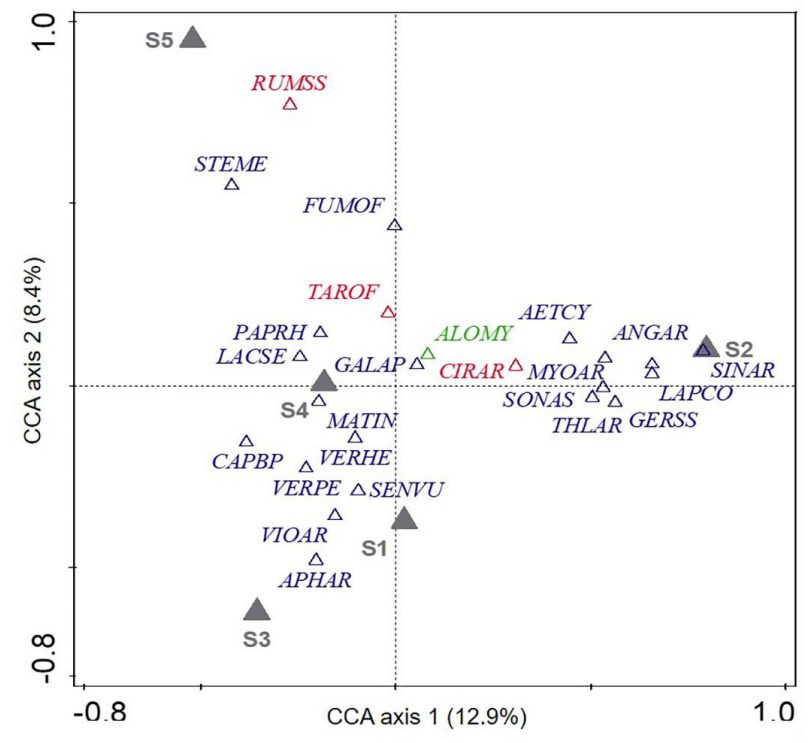

FIGURE 2 | Partial canonical correspondence analysis (pCCA) highlighting the effects of cropping systems (S1-S5) on community composition of the superficial germinable weed seedbank $(\mathbf{A}, P$-value $=0.002$, explained variation $=9.4 \%)$ and in the subsequent winter wheat uniformity trial $(\mathbf{B}, P$-value $=0.002$, explained variance $=22.3 \%$ ) after partialling out the sampling events $(\mathbf{A})$ and field $(\mathbf{A}, \mathbf{B})$ effects. Only the most frequent species $(N=24$, green: annual grass; blue: annual dicots, red: perennial dicots) are represented and named according to their EPPO codes (https://gd.eppo.int/).

Despite differences in soil disturbance between systems, no differences were found in the CMW seed mass.

\section{Legacy Effect of Cropping System on Germination Patterns}

A total of 21 weed species were found in the tilled strips of at least two of the cropping systems, allowing us to compare the distribution of their emergence between cropping systems over the growing season (Figure 4; Supplementary Table 3). In total, 14 out of the 21 species exhibited distributions of emergence that varied between one or more systems (Figure 4). For example, across the five cropping system treatments, a total of 3,814 individuals of $A$. myosuroides germinated over the season (counted prior to six tillage events). The period of germination for A. myosuroides was wider in systems S5 and S3 than in system S4 (Supplementary Table 3). This pattern was also observed for G. aparine, with early germination concentrated in autumn in S1, delayed but still concentrated in autumn in S4, and generally extended over a longer period including spring and summer in systems S3 and S5. Known for being capable of germinating all season, the germination patterns of $S$. media and $V$. persica also varied by system (Figure 4), with more frequent germination occurring in autumn in systems S4 and S3, compared to an extended period of germination across the whole season in system S5. Seedlings of Amaranthus hybridus were observed at many tillage timings over the growing season in the noplow system (S2) but were only observed in the spring/summer periods in the tillage-based S4 and S5 systems (Figure 4). The opposite pattern was observed for $A$. retroflexus, i.e.. only observed in spring/summer in system S2, whereas it was observed emerging over a wider period in autumn in system S5. This difference in emergence periodicity between S2 and the tillagebased systems was also observed for $C$. arvense. Few significance differences were observed for autumn-germinating species (i.e., $V$. hederifolia) or spring/summer-germinating species (e.g., $S$. nigrum, C. polyspermum, C. album). When differences in seedling emergence periodicity were found between S5 and another cropping system for a given species, the species germinated later in S5 (except for A. retroflexus).

\section{DISCUSSION}

\section{Legacy Effects of IWM Systems on Weed Species Richness and Abundance}

We found that 17 years of continuous implementation of IWM resulted in germinable seedbank and emerged weed communities that were more species rich and more abundant than those observed in the reference system, validating our first hypothesis. Higher weed density was also observed in the IWM systems during the initial 17 years of the cropping-system experiment phase; however, this higher weed abundance was not associated with a loss in crop productivity (Adeux et al., 2019a). We hypothesize that even though weed management met its primarily objective, i.e., to prevent annual crop yield losses, it was not as efficient as it was in the reference system. The reduced use of herbicides in the IWM systems, even when replaced by a combination of alternative weed management practices, allowed 


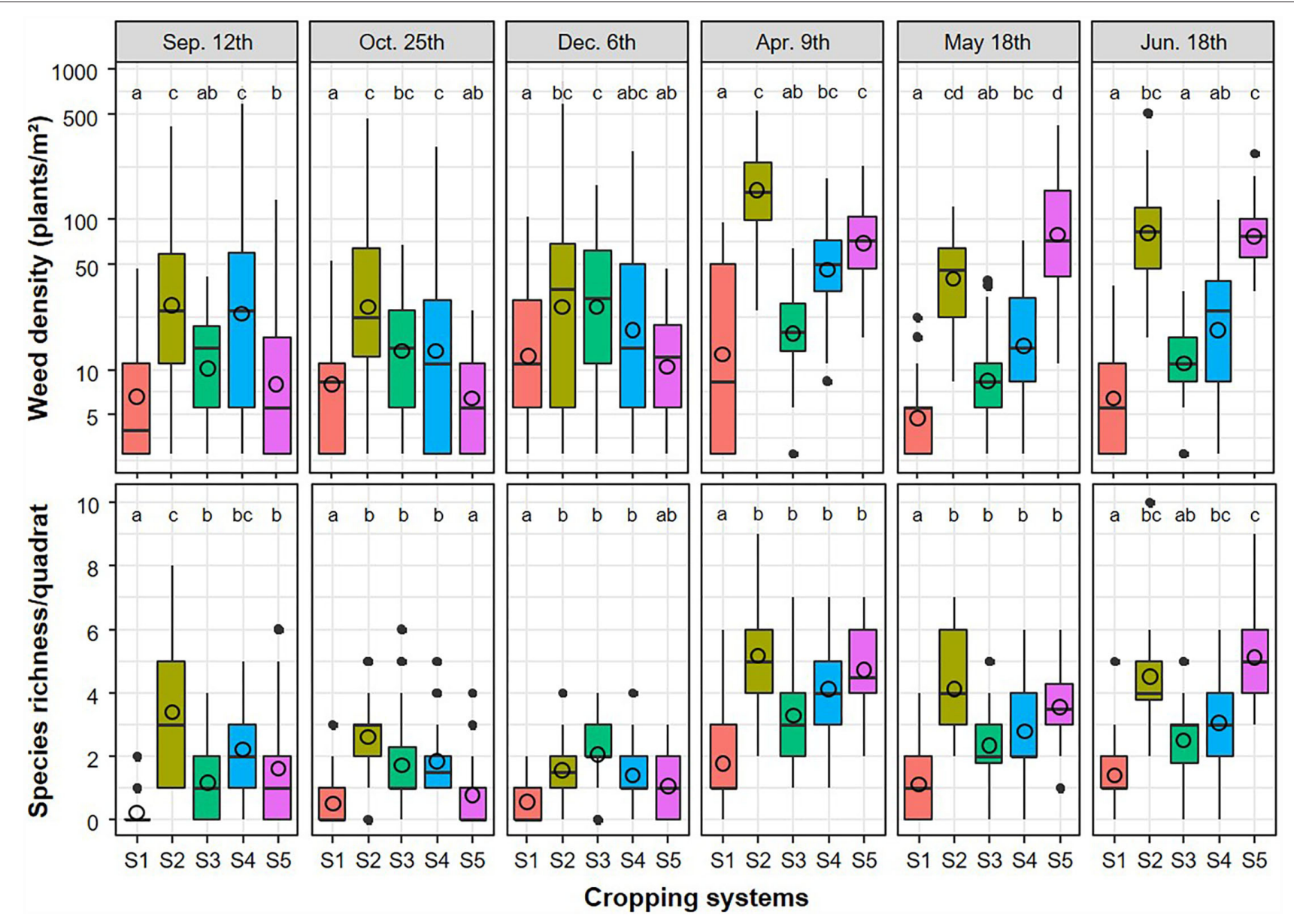

FIGURE 3 | Total weed density and species richness observed in the tilled strips (i.e., in situ superficial germinable seedbank) of the cropping systems (S1-S5) by sampling event (implemented approximately 6 weeks after each tillage event). Weed density model quality: $R^{2} m=0.51, R^{2} C=0.59$; Species richness model quality: $R^{2} m=0.60, R^{2} c=0.65$. Within a sampling event, mean values (open circles) for each systems are not different at $P<0.05$ if they share the same letters.

certain species to complete their life cycles and shed seeds, leading to a more abundant weed seedbank.

Higher weed species richness in the four IWM systems is congruent with many previous studies (synthesized by Cléments et al., 1994), and is partially related to IWM systems having higher diversity of crop types compared to the reference system. Increasing crop diversity through the inclusion of spring and summer crops in the rotation, with the aim of managing autumn-germinating weeds such as A. myosuroides, extended the ecological niche (Mahaut et al., 2019), allowing spring- and summer-germinating species such as $S$. nigrum, A. arvensis, or species capable of germinating all year round such as $S$. media, to establish. Sowing period plays a major role in structuring weed communities within (i.e., delayed sowing, Fried et al., 2012) and across (Fried et al., 2010; Gunton et al., 2011) crops. Differences in herbicide use between the IWM systems likely had little or no effect on species richness, as previously reported (Mahn and Helmecke, 1979; Derksen et al., 1995).

High species richness in the S2 system was likely related to the decrease in soil disturbance as it transitioned to a strict conservation agriculture system (superficial tillage from 2001 to 2010 and no-till from 2010 to 2017). Indeed, conservation agriculture relies on three fundamental pillars, namely diversified crop rotation, permanent soil cover and absence of soil disturbance (Hobbs et al., 2008). While herbicide use in S2 was similar to S1 (Adeux et al., 2019a), S2 mainly relied on glyphosate applications during the summer fallow period. No-till results in weed seeds remaining on the soil surface, a condition deemed unfavorable to weed seed germination, due to poor seed:soil contact (Cordeau et al., 2015), and increased weed seed mortality (Nichols et al., 2015). However, many studies have reported higher weed pressure under no-till than under plowing (Cardina et al., 2002; Adeux et al., 2019a), likely because permanent notill systems provide a stable habitat for a new suite of adapted species (Armengot et al., 2016; Cordeau et al., 2020). In our study, the seedbank assessed in system S2 in 2010, i.e., before the notill phase, was 60 times more abundant than in the reference system (S1) and 1.5 times more abundant than in the herbicidefree system (S5). In addition, 50-80\% of the seedbank in S2 was concentrated in the top soil horizon, and the last 7 years 


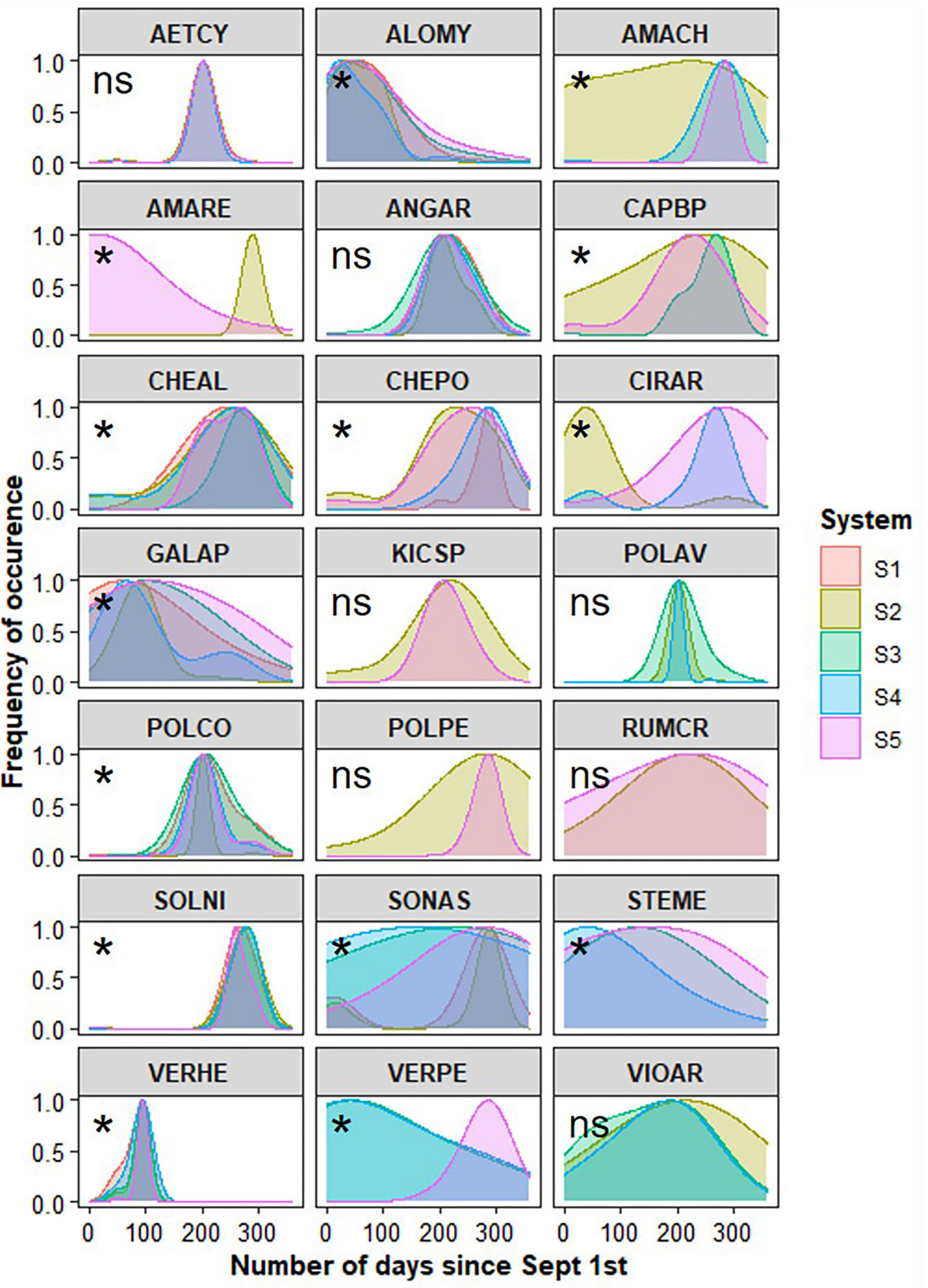

FIGURE 4 | Distribution of emerged seedlings per weed species (named by EPPO code) in each cropping system (S1-S5) during the superficial germinable seedbank experiment in which strips were tilled every 6 weeks over the growing season. Significance of overlap between pairs of systems was tested with a randomization procedure ("at least one overlap is significantly different, ns: no significant difference in overlap, see detailed overlap values and significance in

Supplementary Table 3). 
of no-till phase likely amplified this phenomenon (Chauhan et al., 2006; Vasileiadis et al., 2007; Cordeau et al., 2020). Finally, studies have shown that mulch can suppress weed emergence in no-till cover-crop based systems such as implemented in S2 in the last phase. However, low cover crop productivity during the summer fallow periods of the cropping system experiment did not allow to generate a weed suppressive mulch. The small amount of cover crop residues were incorporated to the soil by the soil fauna during the subsequent crops before having a chance to accumulate.

Weed seedbanks are often assumed to reflect past farming practices. Nevertheless, recent farming practices might have a disproportionate effect on observed seedbanks, compared to practices more distant in time, especially for weed species exhibiting transient seedbanks. Weed species persistence in the soil seedbank is hence a key trait to account for when investigating relationship between farming practices and weed seedbanks.

\section{Legacy Effects of IWM Systems on Taxonomic and Functional Weed Community Composition}

Our study showed that the implementation of contrasting IWM systems over a 17 year period shifted weed community composition, revealed by taxonomic and functional differences in both seedbank and emerged weed communities in winter wheat of the uniformity trial, validating our second hypothesis. Half of the species observed in the germinable seedbank assessed by the tilled strips were observed 7 years earlier in the seedbank, probably due to their high persistence (Lutman et al., 2002). These results highlight that shifts in weed community composition are slow, probably due to the weak filtering effects of many IWM farming practices. Assembly rules in weed community ecology state that each set of farming practices will act as a set of filters on weed species traits (Booth and Swanton, 2002). Tillage, cash crop and direct weed control are often considered to be major filters of weed community composition (Légère et al., 2005; Ryan et al., 2010; Fried et al., 2012).

We found that the cropping systems tested were first discriminated by tillage use (first CCA axis), with S2 associated to perennial and/or Asteraceae taxa, as shown by previous studies (Trichard et al., 2013). Our cropping systems were then discriminated by herbicide use (first CCA axis), favoring species of low stature able to germinate all year round. Higher intensity of herbicide use and higher diversity of herbicide spectrum was found to be associated to shorter flowering duration and late germination, respectively (Fried et al., 2012).

We found a higher CWM height in S2 than in S3, which is intuitive because high tillage intensity is often related to a trait syndrome of annual life history, short stature, small seed size, and early flowering (Fried et al., 2012). The high CWM height in S2 can also be explained by weed species competing for light with the cover crop during the summer fallow period. Canopy height is considered to be a reliable proxy for competitive ability for light, especially for cereal crops (Seavers and Wright, 1999) because competitive outcomes are strongly influenced by hierarchies in resource capture between crop and weeds at crop canopy closure (Adeux et al., 2019b).

We observed a higher CWM for SLA in the herbicide-free S5 system, compared to the other systems. Specific leaf area is an indicator of the efficiency by which leaf biomass is allocated to the production of leaf area (Cavero et al., 2000; Storkey, 2005). Two allocation strategies have been observed in weeds in the literature (Storkey, 2005): a shade-tolerance syndrome that characterizes small-statured weed species with high SLA values, as was observed in system S5, and a shade-avoidance syndrome, which is the most common response in the context of competitive hierarchies among plants, as we observed in system S2. We hypothesize that the repeated mechanical weeding in system S5 stimulated weed germination late in season, which resulted in weed seedlings needing to grow in the shade of the crop.

Finally, contrary to our expectation, the CWM of seed mass did not differ among systems. This was surprising because previous studies have reported that seed mass negatively correlates with tillage intensity (Ghersa and Martinez-Ghersa, 2000; Albrecht and Auerswald, 2009; Storkey et al., 2010). We hypothesize that the relative lack of weed species diversity and high abundance of the relatively large-seeded species $G$. aparine in the S1 system (most intense tillage) contributed to the lack of a similar correlation in our study.

\section{Evidence That IWM Can Lead to Shifts in Emergence Patterns Within Weed Species}

We found that for two thirds of the weed species analyzed, continuous implementation of IWM practices resulted in shifts in their emergence patterns, even after simply 17 years. We observed three general patterns: (i) weed species known to germinate in autumn (e.g., A. myosuroides and G. aparine) extended their germination period in the no-plow S2 system; (ii) phylogenetically-related species belonging to the same genus (e.g., A. retroflexus and A. hybridus) often had divergent patterns of emergence, even in the same system; and (iii) species known to germinate all year round (e.g., $V$. persica and $S$. media) exhibited emergence patterns that were restricted to late in the season in the herbicide-free S5 compared to S3 and S4 systems. We discuss each of these patterns below.

For the 17 year duration of the IWM cropping system experiment, both A. myosuroides and G. aparine were observed to occur nearly exclusively in the winter crops (Adeux et al., 2019a). Our in situ seedbank approach (i.e., tilled strips) revealed that these species emerged in high abundance in spring and summer in some of our systems. A. myosuroides has been noted to germinate when temperatures rise above $0^{\circ} \mathrm{C}$ (Colbach et al., 2002) and emerge in two phases (Naylor, 1972), with the highest peak occurring in autumn $(\sim 80 \%)$ and a lesser peak in spring ( $\sim 20 \%)$. We attribute the higher proportion of $A$. myosuroides seeds germinating in spring, in part, to the selective effect of $17-$ years of repeated false seedbeds coupled with delayed sowing-a typical IWM practice (Rasmussen, 2004) - in the tillage-based IWM systems (S3, S4, S5), which likely selected against the autumn-emerging cohorts. Secondly, environmental conditions may also have played a role. Indeed, the winter of the uniformity 
trial was mild and A. myosuroides emerged in a period of the year where usually, already emerged seedlings are in vegetative rest and seeds wait for favorable conditions in the spring to germinate when temperature increases (Colbach et al., 2002). In addition, in the years preceding the uniformity trial, weather conditions prior to cereal harvest i.e. when A. myosuroides shed seeds (in June 2016 and 2017, Supplementary Figure 2), were hot and dry, conditions known to decrease seed dormancy (Colbach et al., 2002; Menegat et al., 2018). These conditions may have led to early germination (e.g., August). However, summer and autumn 2017 (uniformity trial) were hot and dry (Supplementary Figure 1), conditions which are not favorable for germination (Colbach et al., 2002), thus shifting germination to the following winter and spring, and explaining the stretch of the germination period. That weather conditions likely played a role is also supported by the fact that, while the soil seedbank is considered to reflect the effect of past farming history, expression of the germinable seedbank tends to more strongly reflect the effects of more recent farming practices non-persistent seeds such as A. myrosuroides (Moss, 1985). Emergence of G. aparine is expected to occur from October to January, with few individuals emerging in spring (Taylor, 1999), despite plasticity in the timing of seed germination (Kutsch and Kappen, 1991). G. aparine seeds are relatively large and not adapted to germinate on the soil surface and in dry conditions (Cordeau et al., 2018). We hypothesize that the continuous no-till phase in S2 (2010-2017) delayed the G. aparine germination period to more favorable conditions. Indeed, during winter and early spring, natural burial occurs (Benvenuti, 2007), particularly in our clay soils, due to changes in soil structure in response to freeze/thaw and humectation/desiccation phases. In addition, conservation agriculture systems, such as S2, are known to harbor a high diversity of organisms, such as earthworms (Smith et al., 2008), which are active in winter/spring and capable or burying seeds (Smith et al., 2005), which could favor germination of $G$. aparine.

$A$. retroflexus and $A$. hybridus differed in their germination patterns in the no-plow S2 system. Germination of $A$. retroflexus occurred strictly in summer, while germination of $A$. hybridus occurred throughout the season. This was unexpected given their phylogenetic similarity, as well as the fact that the literature does not indicate major differences in germination requirements or phenology between the species (Weaver and McWilliams, 1980; Costea et al., 2004). While A. hybridus tends to germinate at lower temperatures, both species exhibit a variable dormancy and polymorph germination as a result of maternal, genetic and environmental factors (Costea et al., 2004). Since their seeds were persistent in the soil seedbank (Costea et al., 2004; Steckel et al., 2007), we hypothesize that A. retroflexus and $A$. hybridus seeds were produced before and after the transition to the strict no-till phase in 2010, respectively. Thus, $A$. retroflexus seeds persisted in the soil seedbank and remained adapted to germinate late in season, whereas $A$. hybridus seeds were located close to the soil surface, exposed to environmental conditions, and thus acquired the capacity to germinate at different timings of the year. Unfortunately, we cannot confirm this hypothesis by looking at the seedbank in
2010 because Amaranthus species were not discriminated at the species level.

Finally, we observed species such as $V$. persica and $S$. media, known to germinate all year round, which exhibited a germination periodicity that was restricted to late in the season is some systems. This was particularly evident when comparing germination patterns of these species in the herbicide-free S5 system with the herbicide-based S3 and the typical IWM S4 system (i.e., implementing mechanical weeding and herbicides later in season if needed). Indeed, repeated mechanical weeding over the crop season in S5 controlled weeds but also stimulated emergence (Bond and Grundy, 2001). We hypothesize that the last mechanical weeding stimulated the emergence of weeds, which thereafter were uncontrolled other than the suppressive effect of the crop canopy (Van Der Meulen and Chauhan, 2017). This was not the case in S3 and S4 because weeds were managed with herbicide all year round (in S3) or at the last weeding (in S4), thus eliminating weeds without stimulating new emergence. Thus, we hypothesize that $V$. persica and S. media had to germinate late in season and shed seeds before the primary tillage implemented after crop harvest to maintain their populations in S5 over time, explaining their restricted germination period.

To conclude on the shift of emergence patterns, we hypothesize that (i) weeds have experienced selective pressures that resulted in shifts in their emergence and that (ii) there were differences in biotic and abiotic environments during the last couple of years of the cropping system experiment that resulted in differences being observed in the uniformity year only. High densities of certain weed species observed during the uniformity trial may result from specific weather conditions that occurred during the last years of the cropping system experiment (Supplementary Figure 2). Nevertheless, we argue that shifts in emergence timing can be related to past selective pressures, at least for species with persistent seedbanks.

\section{Methods to Assess the Legacy Effects of Past Cropping Systems on Weeds}

A primary rationale for this study was to assess the legacy effects of four contrasting cropping systems managed with IWM principles in comparison to a reference system, on the weed seedbank and on weed communities emerging in a subsequent, uniformly managed winter wheat crop. The seedbank was evaluated in situ, using a novel "tilled strips" approach in which strips of soil were disturbed every 6 weeks in order to stimulate weed seedling emergence over the period of investigation, as suggested by previous studies (Cordeau et al., $2017 a, b, c)$. Half of the species observed in the tilled strips were also observed in the seedbank analyzed with a sieving method 7 years earlier. Considering the low persistence of some autumn-germinating grass species we observed (Lutman et al., 2002), we consider the tilled strips method to be effective in reflecting the germinable seedbank resulting from the past cropping system treatments. While the tilled strips method is less demanding in human labor compared to other methods (Mahé et al., 2021), it does preclude the ability to grow and harvest a crop during the study period, something to consider 
if similar approaches are to be adopted on farmers' fields. Jernigan et al. (2017) proposed a succession of two uniformity trials, one initiated in autumn with oat and one in spring with sorghum/millet, so as to harvest forage cover crops while assessing the legacy effect of past cropping systems at two crucial cropping periods.

To examine the legacy effects of the previous cropping systems on the emerging weed community, we managed uniformly, i.e., with the same practices (e.g., primary and secondary tillage, seeding date and rate, weeding tactics), a sole crop of winter wheat. Deciding exactly which farming practices to implement during the uniformity trial, so as to most effectively reveal the legacy effects of the past systems, was no easy task. Mouldboard plowing was excluded because it would have buried the seedbank accumulated in the superficial horizon in the no-plow S2 system (Colbach et al., 2000), thus masking the legacy effects of that system (Cordeau et al., 2020). Following the same principles as implemented over the past 17 years (Adeux et al., 2019a), e.g., systematic plowing in the reference-S1 and no-plow in S2, would have led to confounding factors, since differences in weed communities may have resulted from the combined effects of past practices (the one we wanted to assess) and the tillage practices of the uniformity trial. We thus decided to superficially till all fields, which was efficient to reveal the legacy effect, but probably resulted in an over estimation of total weed density in the no-plow S2 system compared to the other systems (Blanco-Canqui and Wortmann, 2020; Cordeau et al., 2020).

Finally, the legacy effects were studied with weed surveys implemented before weeding only because no differences were observed after spring herbicide treatment (data not shown here, but confirmed by a joint experiment on the same site:year in the no-plow S2 system, Cordeau et al., 2020). This highlights the tremendous capacity of herbicides to homogenize initially contrasted weed flora and the difficulty to link agronomic practices and weed observations, when the latter are made after weeding (Colbach et al., 2020).

\section{CONCLUSION}

We assessed the legacy effects of IWM cropping systems implemented over 17 years on the superficial germinable weed seedbank and emerged weed flora in a uniformly managed winter wheat trial conducted in year 18 . We concluded that the resulting weed communities in IWM systems were more species-rich and more abundant than those observed in the reference system, and differed in terms of taxonomic and functional composition. In addition, we found that, when systems shared the same species, germination patterns of two-thirds of the weed species differed between systems. Increasing the diversity of agroecological levers to manage weeds in IWM systems allows for decreased herbicide use (Adeux et al., 2019a; Colbach et al., 2020) while limiting yield loss (Adeux et al., 2019a) and diversifying weed communities. Finally, our new method to assess the superficial germinable seedbank in situ with tilled strips was inexpensive and effective in revealing the legacy effects of IWM systems on weed communities. We showed that the long-term effect of IWM systems may shift the emergence patterns of some weed species. We discuss that diversified crop rotation, no-till, repeated false seed bed and delayed sowing may be the main IWM practices responsible for this shift. This information can be used to forecast future weed community dynamics and redesign cropping systems to move toward more agroecological systems that provide a more robust portfolio of ecosystem services while limiting disservices (Hunter et al., 2017; Petit et al., 2018; Vanbergen et al., 2020).

\section{DATA AVAILABILITY STATEMENT}

The raw data supporting the conclusions of this article will be made available by the authors, upon request.

\section{AUTHOR CONTRIBUTIONS}

SC, NM-J, PF, and GA designed the study. SC and NM-J funded the experiment. SC, AB, HB, EV, NM-J, and GA planned data collection. SC, AB, HB, EV, and GA collected the data. SC, $\mathrm{AB}$, and $\mathrm{GA}$ analyzed the data. All authors were involved in the interpretation of the results and contributed to writing the original version of the manuscript and improving the subsequent ones.

\section{FUNDING}

$\mathrm{AB}$ was funded by the Casdar project VANCOUVER, which was financed by the French Ministry in charge of Agriculture and Food (Ministère de l'Agriculture et de l'Alimentation), with financial contributions from the special purpose account Développement agricole et rural. The authors also wish to acknowledge financial support from the French project CoSAC (ANR-15-CE18-0007), the French program Investissements d'Avenir, ANR PPR SPECIFICS project (ANR-20-PCPA-0008), and the project ISITE-BFC (contract ANR-15-IDEX-03).

\section{ACKNOWLEDGMENTS}

Authors would like to thank all members of the INRA Research Station Domaine d'Epoisses who helped to design the experiment and who carried it out with dedication (Loïc Dumont, Brice Mosa, Philippe Chamoy, Benjamin Pouilly, Alain Berthier). This experiment would not have been possible if NM-J (INRA UMR Agroécologie) had not started a Long-Term Integrated Weed Management Cropping System Experiment in 2000.

\section{SUPPLEMENTARY MATERIAL}

The Supplementary Material for this article can be found online at: https://www.frontiersin.org/articles/10.3389/fagro. 2021.769992/full\#supplementary-material 


\section{REFERENCES}

Adeux, G., Munier-Jolain, N., Meunier, D., Farcy, P., Carlesi, S., Barberi, P., et al. (2019a). Diversified grain-based cropping systems provide long-term weed control while limiting herbicide use and yield losses. Agron. Sustain. Dev. 39, 42. doi: 10.1007/s13593-019-0587-x

Adeux, G., Vieren, E., Carlesi, S., Bàrberi, P., Munier-Jolain, N., and Cordeau, S. (2019b). Mitigating crop yield losses through weed diversity. Nat. Sustain. 2, 1018-1026. doi: 10.1038/s41893-019-0415-y

Adeux, G., Yvoz, S., Biju-Duval, L., Cadet, E., Farcy, P., Fried, G., et al. (2022). Cropping system diversification does not always beget weed diversity. Eur. J. Agron. 133, 126438. doi: 10.1016/j.eja.2021.126438

Albrecht, H., and Auerswald, K. (2009). Seed traits in arable weed seed banks and their relationship to land-use changes. Basic Appl. Ecol. 10, 516-524. doi: 10.1016/j.baae.2009.02.002

Armengot, L., Blanco-Moreno, J. M., Bàrberi, P., Bocci, G., Carlesi, S., Aendekerk, R., et al. (2016). Tillage as a driver of change in weed communities: a functional perspective. Agric. Ecosyst. Environ. 222, 276-285. doi: 10.1016/j.agee.2016.02.021

Bàrberi, P., and Lo Cascio, B. (2001). Long-term tillage and crop rotation effects on weed seedbank size and composition. Weed Res. 41, 325-340. doi: 10.1046/j.1365-3180.2001.00241.x

Barralis, G. (1976). "Méthode d'étude des groupements adventices des cultures annuelles," in Ve Colloque International sur l'Ecologie et la Biologie des Mauvaises Herbes (Paris: Columa). p. 59-68.

Benvenuti, S. (2007). Natural weed seed burial: effect of soil texture, rain and seed characteristics. Seed Sci. Res. 17, 211-219. doi: 10.1017/S0960258507782752

Blanco-Canqui, H., and Wortmann, C. S. (2020). Does occasional tillage undo the ecosystem services gained with no-till? A review. Soil Till. Res. 198, 104534. doi: $10.1016 /$ j.still.2019.104534

Bond, W., and Grundy, A. (2001). Non-chemical weed management in organic farming systems. Weed Res. 41, 383-405. doi: $10.1046 /$ j.1365-3180.2001.00246.x

Booth, B. D., and Swanton, C. J. (2002). Assembly theory applied to weed communities. Weed Sci. 50, 2-13. doi: 10.1614/0043-1745(2002)0500002:AIATAT2.0.CO;2

Bourgeois, B., Munoz, F., Fried, G., Mahaut, L., Armengot, L., Denelle, P., et al. (2019). What makes a weed a weed? A large-scale evaluation of arable weeds through a functional lens. Amer. J. Bot. 106, 90-100. doi: 10.1002/ajb2.1213

Brown, B., and Gallandt, E. R. (2018). A systems comparison of contrasting organic weed management strategies. Weed Sci. 66, 109-120. doi: 10.1017/wsc.2017.34

Cardina, J., Herms, C. P., and Doohan, D. J. (2002). Crop rotation and tillage system effects on weed seedbanks. Weed Sci. 50, 448-460. doi: 10.1614/0043-1745(2002)0500448:CRATSE2.0.CO;2

Cavero, J., Zaragoza, C., Bastiaans, L., Suso, M.l, and Pardo, A. (2000). The relevance of morphological plasticity in the simulation of competition between maize and Datura stramonium. Weed Res. 40, 163-180. doi: 10.1046/j.1365-3180.2000.00176.x

Chauhan, B. S., Gill, G., and Preston, C. (2006). Influence of tillage systems on vertical distribution, seedling recruitment and persistence of rigid ryegrass (Lolium rigidum) seed bank. Weed Sci. 54, 669-676. doi: 10.1614/WS-05-184R.1

Cléments, D. R., Weise, S. F., and Swanton, C. J. (1994). Integrated weed management and weed species diversity. Phytoprotection 75, 1-18. doi: $10.7202 / 706048$ ar

Colbach, N., Chauvel, B., Dürr, C., and Richard, G. (2002). Effect of environmental conditions on Alopecurus myosuroides germination. I. Effect of temperature and light. Weed Res. 42, 210-221. doi: 10.1046/j.0043-1737.2002.00279.x

Colbach, N., Petit, S., Chauvel, B., Deytieux, V., Lechenet, M., Munier-Jolain, N., et al. (2020). The pitfalls of relating weeds, herbicide use and crop yield: don't fall into the trap! A critical review. Front. Agron. 2, 615470. doi: $10.3389 /$ fagro. 2020.615470

Colbach, N., Roger-Estrade, J., Chauvel, B., and Caneill, J. (2000). Modelling vertical and lateral seed bank movements during moulboard ploughing. Eur. J. Agron. 13, 111-124. doi: 10.1016/S1161-0301(00)00069-1

Cordeau, S., Baudron, A., and Adeux, G. (2020). Is tillage a suitable option for weed management in conservation agriculture? Agronomy 10, 1746. doi: 10.3390/agronomy10111746
Cordeau, S., Guillemin, J. P., Reibel, C., and Chauvel, B. (2015). Weed species differ in their ability to emerge in no-till systems that include cover crops. Ann. Appl. Biol. 166, 444-455. doi: 10.1111/aab.12195

Cordeau, S., Smith, R. G., Gallandt, E. R., Brown, B., Salon, P., Ditommaso, A., et al. (2017a). Disentangling the effects of tillage timing and weather on weed community assembly. Agriculture 7, 66. doi: 10.3390/agriculture7080066

Cordeau, S., Smith, R. G., Gallandt, E. R., Brown, B., Salon, P., Ditommaso, A., et al. (2017b). How do weeds differ in their response to the timing of tillage? A study of 61 species across the Northeastern United States. Ann. Appl. Biol. 171, 340-352. doi: 10.1111/aab.12377

Cordeau, S., Smith, R. G., Gallandt, E. R., Brown, B., Salon, P., Ditommaso, A., et al. (2017c). Timing of tillage as a driver of weed communities. Weed Sci. 65 , 504-514. doi: 10.1017/wsc.2017.26

Cordeau, S., Wayman, S., Reibel, C., Strbik, F., Chauvel, B., and Guillemin, J. P. (2018). Effects of drought on weed emergence and growth vary with seed burial depth and presence of a cover crop. Weed Biol. Manag. 18, 12-25. doi: $10.1111 /$ wbm.12136

Costea, M., Weaver, S. E., and Tardif, F. J. (2004). The biology of Canadian weeds. 130. Amaranthus retroflexus L., A-powellii S. Watson and A-hybridus L. Canad. J. Plant Sci. 84, 631-668. doi: 10.4141/P02-183

Derksen, D. A., Anderson, R. L., Blackshaw, R. E., and Maxwell, B. (2002). Weed dynamics and management strategies for cropping systems in the northern Great Plains. Agron. J. 94, 174-185. doi: 10.2134/agronj2002.1740

Derksen, D. A., Thomas, A. G., Lafond, G. P., Loeppky, H. A., and Swanton, C. J. (1995). Impact of post-emergence herbicides on weed community diversity within conservation-tillage systems. Weed Res. 35, 311-320. doi: 10.1111/j.1365-3180.1995.tb01794.x

Fried, G., Kazakou, E., and Gaba, S. (2012). Trajectories of weed communities explained by traits associated with species' response to management practices. Agric. Ecosyst. Environ. 158, 147-155. doi: 10.1016/j.agee.2012.06.005

Fried, G., Petit, S., and Reboud, X. (2010). A specialist-generalist classification of the arable flora and its response to changes in agricultural practices. BMC Ecol. 10, 20. doi: 10.1186/1472-6785-10-20

Gaba, S., Perronne, R., Fried, G., Gardarin, A., Bretagnolle, F., Biju-Duval, L., et al. (2017). Response and effect traits of arable weeds in agro-ecosystems: a review of current knowledge. Weed Res. 57, 123-147. doi: 10.1111/wre.12245

Ghersa, C., and Martinez-Ghersa, M. (2000). Ecological correlates of weed seed size and persistence in the soil under different tilling systems: implications for weed management. Field Crops Res. 67, 141-148. doi: 10.1016/S0378-4290(00)00089-7

Gunton, R. M., Petit, S., and Gaba, S. (2011). Functional traits relating arable weed communities to crop characteristics. J. Veget. Sci. 22, 541-550. doi: 10.1111/j.1654-1103.2011.01273.x

Harker, K. (2013). Slowing weed evolution with integrated weed management. Canad. J. Plant Sci. 93, 759-764. doi: 10.4141/cjps2013-049

Harker, N., and O'donovan, J. T. (2013). Recent weed control, weed management, and integrated weed management. Weed Technol. 27, 1-11. doi: 10.1614/WT-D-12-00109.1

Hobbs, P. R., Sayre, K., and Gupta, R. (2008). The role of conservation agriculture in sustainable agriculture. Philos. Trans. Roy. Soc. B Biol. Sci. 363, 543-555. doi: $10.1098 /$ rstb.2007.2169

Hunter, M. C., Smith, R. G., Schipanski, M. E., Atwood, L. W., and Mortensen, D. A. (2017). Agriculture in 2050: recalibrating targets for sustainable intensification. Bioscience 67, 386-391. doi: 10.1093/biosci/bix010

Jernigan, A. B., Caldwell, B. A., Cordeau, S., Ditommaso, A., Drinkwater, L. E., Mohler, C. L., et al. (2017). Weed abundance and community composition in a long-term organic vegetable cropping systems trial. Weed Sci. 65, 639-649. doi: $10.1017 /$ wsc. 2017.33

Kutsch, W. L., and Kappen, L. (1991). "Chapter 7 - Plasticity of the photosynthetic production of Galium aparine L.," in Modern Ecology, eds G. Esser, and D. Overdieck (Amsterdam: Elsevier), 113-131. doi: 10.1016/B978-0-444-89183-9.50012-5

Lechenet, M., Deytieux, V., Antichi, D., Aubertot, J.-N., Bàrberi, P., Bertrand, M., et al. (2017). Diversity of methodologies to experiment Integrated Pest Management in arable cropping systems: analysis and reflections based on a European network. Eur. J. Agron. 83, 86-99. doi: 10.1016/j.eja.2016.09.012

Légère, A., Stevenson, F. C., and Benoit, D. L. (2005). Diversity and assembly of weed communities: contrasting responses across cropping 
systems. Weed Res. 45, 303-315. doi: 10.1111/j.1365-3180.2005. 00459.x

Liebman, M., and Gallandt, E. (1997). "Many little hammers: ecological management of crop-weed interactions," in Ecology in Agriculture, ed. J. Le (New York, NY: Academic Press), 291-343. doi: 10.1016/B978-012378260-1/50010-5

Lutman, P. J. W., Cussans, G. W., Wright, K. J., Wilson, B. J., Wright, G. M., and Lawson, H. M. (2002). The persistence of seeds of 16 weed species over six years in two arable fields. Weed Res. 42, 231-241. doi: 10.1046/j.0043-1737.2002.00281.x

Mahaut, L., Gaba, S., and Fried, G. (2019). A functional diversity approach of crop sequences reveals that weed diversity and abundance show different responses to environmental variability. J. Appl. Ecol. 56, 1400-1409. doi: 10.1111/1365-2664.13389

Mahé, I., Cordeau, S., Bohan, D. A., Derrouch, D., Dessaint, F., Millot, D., et al. (2021). Soil seedbank: Old methods for new challenges in agroecology? Ann. Appl. Biol. 178, 23-38. doi: 10.1111/aab.12619

Mahn, E. G., and Helmecke, K. (1979). Effects of herbicide treatment on the structure and functioning of agro-ecosystems II. Structural changes in the plant community after the application of herbicides over several years. Agro Ecosyst. 5, 159-179. doi: 10.1016/0304-3746(79)90015-5

Menalled, F. D., Peterson, R. K., Smith, R. G., Curran, W. S., Páez, D. J., and Maxwell, B. D. (2016). The eco-evolutionary imperative: revisiting weed management in the midst of an herbicide resistance crisis. Sustainability 8, 1297. doi: $10.3390 /$ su8121297

Menegat, A., Milberg, P., Nilsson, A. T., Andersson, L., and Vico, G. (2018). Soil water potential and temperature sum during reproductive growth control seed dormancy in Alopecurus myosuroides Huds. Ecol. Evol. 8, 7186-7194. doi: $10.1002 /$ ece 3.4249

Moss, S. (1985). The survival of Alopecurus myosuroides Huds. seeds in soil. Weed Res. 25, 201-211. doi: 10.1111/j.1365-3180.1985.tb00636.x

Naylor, R. (1972). Biological flora of the British Isles. No. 129 Alopecurus myosuroides Huds.(A. agrestis L.). J. Ecol. 60, 611-622. doi: 10.2307/2258364

Neve, P., Barney, J. N., Buckley, Y., Cousens, R. D., Graham, S., Jordan, N. R., et al. (2018). Reviewing research priorities in weed ecology, evolution and management: a horizon scan. Weed Res. 58, 250-258. doi: 10.1111/wre.12304

Nichols, V., Verhulst, N., Cox, R., and Govaerts, B. (2015). Weed dynamics and conservation agriculture principles: a review. Field Crops Res. 183, 56-68. doi: 10.1016/j.fcr.2015.07.012

Oerke, E. C. (2006). Crop losses to pests. J. Agric. Sci. 144, 31. doi: $10.1017 /$ S0021859605005708

Perronne, R., Gaba, S., Cadet, E., and Le Corre, V. (2014). The interspecific and intraspecific variation of functional traits in weeds: diversified ecological strategies within arable fields. Acta Bot. Gall. Bot. Lett. 161, 243-252. doi: 10.1080/12538078.2013.868320

Petit, S., Cordeau, S., Chauvel, B., Bohan, D., Guillemin, J.-P., and Steinberg, C. (2018). Biodiversity-based options for arable weed management. A review. Agron. Sustain. Dev. 38, 48. doi: 10.1007/s13593-018-0525-3

Petit, S., Munier-Jolain, N., Bretagnolle, V., Bockstaller, C., Gaba, S., Cordeau, S., et al. (2015). Ecological intensification through pesticide reduction: weed control, weed biodiversity and sustainability in arable farming. Environ. Manage. 56, 1078-1090. doi: 10.1007/s,00267-015-0554-5

R Development Core Team. (2019). R: A Language and Environment for Statistical Computing. Vienna: the R Foundation for Statistical Computing.

Rasmussen, I. A. (2004). The effect of sowing date, stale seedbed, row width and mechanical weed control on weeds and yields of organic winter wheat. Weed Res. 44, 12-20. doi: 10.1046/j.1365-3180.2003.00367.x

Ryan, M. R., Mirsky, S. B., Mortensen, D. A., Teasdale, J. R., and Curran, W. S. (2011). Potential synergistic effects of cereal rye biomass and soybean planting density on weed suppression. Weed Sci. 59, 238-246. doi: 10.1614/WS-D-10-00110.1

Ryan, M. R., Smith, R. G., Mirsky, S. B., Mortensen, D. A., and Seidel, R. (2010). Management filters and species traits: weed community assembly in long-term organic and conventional systems. Weed Sci. 58, 265-277. doi: 10.1614/WS-D-09-00054.1

Seavers, G., and Wright, K. (1999). Crop canopy development and structure influence weed suppression. Weed Res. 39, 319-328. doi: 10.1046/j.1365-3180.1999.00148.x

Smith, R., Gross, K., and Januchowski, S. (2005). Earthworms and weed seed distribution in annual crops. Agric. Ecosyst. Environ. 108, 363-367. doi: 10.1016/j.agee.2005.01.014

Smith, R. G., Mcswiney, C. P., Grandy, A. S., Suwanwaree, P., Snider, R. M., and Robertson, G. P. (2008). Diversity and abundance of earthworms across an agricultural land-use intensity gradient. Soil Till. Res. 100, 83-88. doi: 10.1016/j.still.2008.04.009

Steckel, L. E., Sprague, C. L., Stoller, E. W., Wax, L. M., and Simmons, F. W. (2007). Tillage, cropping system, and soil depth effects on common waterhemp (Amaranthus rudis) seed-bank persistence. Weed Sci. 55, 235-239. doi: 10.1614/WS-06-198

Storkey, J. (2005). Modelling assimilation rates of 14 temperate arable weed species as a function of the environment and leaf traits. Weed Res. 45, 361-370. doi: 10.1111/j.1365-3180.2005.00466.x

Storkey, J., Moss, S. R., and Cussans, J. W. (2010). Using assembly theory to explain changes in a weed flora in response to agricultural intensification. Weed Sci. 58, 39-46. doi: 10.1614/WS-09-096.1

Taylor, K. (1999). Galium aparine L. J. Ecol. 87, 713-730. doi: 10.1046/j.1365-2745.1999.00381.x

Trichard, A., Alignier, A., Chauvel, B., and Petit, S. (2013). Identification of weed community traits response to conservation agriculture. Agric. Ecosyst. Environ. 179, 179-186. doi: 10.1016/j.agee.2013.08.012

Van Der Meulen, A., and Chauhan, B. S. (2017). A review of weed management in wheat using crop competition. Crop Prot. 95, 38-44. doi: 10.1016/j.cropro.2016.08.004

Vanbergen, A. J., Aizen, M. A., Cordeau, S., Garibaldi, L. A., Garratt, M. P. D., Kovács-Hostyánszki, A., et al. (2020). Transformation of agricultural landscapes in the Anthropocene: nature's contributions to people, agriculture and food security. Adv. Ecol. Res. 63, 193-253. doi: 10.1016/bs.aecr.2020.08.002

Vasileiadis, V. P., Froud-Williams, R. J., and Eleftherohorinos, I. G. (2007). Vertical distribution, size and composition of the weed seedbank under various tillage and herbicide treatments in a sequence of industrial crops. Weed Res. 47, 222-230. doi: 10.1111/j.1365-3180.2007.00564.x

Weaver, S. E., and McWilliams, E. L. (1980). The biology of Canadian weeds.: 44. Amaranthus retroflexus L., A. powellii S. Wats. and A. hybridus L. Canad. J. Plant Sci. 60, 1215-1234. doi: 10.4141/cjps80-175

Weisberger, D., Nichols, V., and Liebman, M. (2019). Does diversifying crop rotations suppress weeds? A meta-analysis. Plos ONE 14, e0219847. doi: 10.1371/journal.pone.0219847

Conflict of Interest: The authors declare that the research was conducted in the absence of any commercial or financial relationships that could be construed as a potential conflict of interest.

Publisher's Note: All claims expressed in this article are solely those of the authors and do not necessarily represent those of their affiliated organizations, or those of the publisher, the editors and the reviewers. Any product that may be evaluated in this article, or claim that may be made by its manufacturer, is not guaranteed or endorsed by the publisher.

Copyright () 2022 Cordeau, Baudron, Busset, Farcy, Vieren, Smith, Munier-Jolain and Adeux. This is an open-access article distributed under the terms of the Creative Commons Attribution License (CC BY). The use, distribution or reproduction in other forums is permitted, provided the original author(s) and the copyright owner(s) are credited and that the original publication in this journal is cited, in accordance with accepted academic practice. No use, distribution or reproduction is permitted which does not comply with these terms. 